IZA DP No. 9725

The Causal Effects of World War II Military Service

Alex Cousley

Peter Siminski

Simon Ville

February 2016 


\title{
The Causal Effects of World War II Military Service
}

\author{
Alex Cousley \\ University of Wollongong
}

Peter Siminski

University of Wollongong

and IZA

Simon Ville

University of Wollongong

\section{Discussion Paper No. 9725 \\ February 2016}

\author{
IZA \\ P.O. Box 7240 \\ 53072 Bonn \\ Germany \\ Phone: +49-228-3894-0 \\ Fax: +49-228-3894-180 \\ E-mail: iza@iza.org
}

Any opinions expressed here are those of the author(s) and not those of IZA. Research published in this series may include views on policy, but the institute itself takes no institutional policy positions. The IZA research network is committed to the IZA Guiding Principles of Research Integrity.

The Institute for the Study of Labor (IZA) in Bonn is a local and virtual international research center and a place of communication between science, politics and business. IZA is an independent nonprofit organization supported by Deutsche Post Foundation. The center is associated with the University of Bonn and offers a stimulating research environment through its international network, workshops and conferences, data service, project support, research visits and doctoral program. IZA engages in (i) original and internationally competitive research in all fields of labor economics, (ii) development of policy concepts, and (iii) dissemination of research results and concepts to the interested public.

IZA Discussion Papers often represent preliminary work and are circulated to encourage discussion. Citation of such a paper should account for its provisional character. A revised version may be available directly from the author. 
IZA Discussion Paper No. 9725

February 2016

\section{ABSTRACT}

\section{The Causal Effects of World War II Military Service ${ }^{1}$}

The effects of military service have been studied for decades, but surprisingly few studies have estimated the effects of World War II (WW2) service, where the focus has been on the impact of this 'total war' on the broader civilian population. Over $90 \%$ of Australian males born in the early 1920s served in the military during WW2. Almost none of those born in the late 1920s served. Treating such cohort differences as exogenous, we conduct one of the first econometric studies of WW2 service. We consider major life outcomes including employment, marital status and home ownership, all measured in 1966, while the economy was strong and male employment was very high. We find a significant negative effect on employment, half of which is accompanied by pensioner status. We find positive effects on home ownership and on separation/divorce. A feature of our analysis is a novel visual depiction of the variation which identifies the estimates, drawing on the Frisch-Waugh theorem.

JEL Classification: H56, N37, N47

Keywords: military service, Australia, World War Two, Frisch-Waugh theorem

Corresponding author:

Peter Siminski

School of Accounting, Economics, and Finance

University of Wollongong

Northfields Avenue

Wollongong, NSW 2522

Australia

E-mail: siminski@uow.edu.au

\footnotetext{
${ }^{1}$ We are grateful to Denzil Fiebig, Alfredo Paloyo and Tim Hatton, for useful discussions and comments. We thank the Department of Veterans' Affairs and Australian Bureau of Statistics for access and assistance with de-identified data. Siminski acknowledges grant support from the Australian Research Council (DE120101642).
} 


\section{Introduction}

For decades, economists have studied the effects of military service on servicemen. The desirability of conscription versus all-volunteer military has motivated some of this work (Friedman, 1967; Oi, 1967), as has estimating the full cost of conflicts (Stiglitz \& Bilmes, 2008). A more recent motivation is veterans' compensation design in light of renewed concern about the extent of post-traumatic stress disorder suffered by servicemen in recent conflicts (Autor et al., 2011; Siminski, 2013). Empirical work has focused on the effects of service on earnings (Angrist, 1990; Angrist \& Krueger, 1994; Imbens and van der Klaauw, 1995; Bauer et al., 2012; Siminski, 2013) and on health (Angrist et al., 1996; Angrist et al., 2010; Dobkin and Shabani, 2009; Johnston et al., 2015). ${ }^{2}$

Surprisingly few studies in this literature have estimated the effects of World War Two (WW2) service. WW2 had a devastating effect globally, with at least 60 million individuals, mostly civilians, losing their lives. The events of WW2 surpassed World War One in its 'utter ruthlessness', due to advances in military technology, especially aerial bombardment of major cities (Marwick 1974, p2). The focus of research has therefore tended towards studying the effects of war on broad populations.

WW2 was particularly significant for Australia, as it was the first time that it faced the threat of invasion, requiring a full mobilisation of the economy (Beaumont 1996). As part of this mobilisation, conscription on wartime service was introduced in Australia for the first time and almost a million Australians entered armed service, with hundreds of thousands more in auxiliary and war industries (Lloyd and Rees 1994). This represented more than 1 in 5 of the adult population or 2 in 5 of the adult male population (ABS Yearbook 1938, pp. 351, 376). Previous research has consisted largely of oral and archival historical work. Garton (1996) and Damousi (2001) look at the effects of military service on the families of servicemen and servicemen themselves, respectively. Garton (1996) suggests that military service had a negative impact on employment prospects, especially for those individuals who were captured prisoner of war.

\footnotetext{
${ }^{2}$ Other outcomes that have been studied include crime (Galiani et al., Lindo \& Stoecker, Siminski et al. 2016), education (Angrist and Chen 2010); marital and family outcomes (Conley \& Heerwig, 2013).
} 
We know of no econometric work on the effects of WW2 service for Australians. We address this gap by conducting the first econometric study of the effects of WW2 service on the major life outcomes of Australian servicemen. The only quasi-experimental studies we are aware of for WW2 are for the United States: Angrist \& Kreuger (1994) estimated earnings effects, while Fetter (2013) studied housing outcomes.

A key challenge for estimating causal effects of military service is selection bias. In particular, military personnel are much healthier than the general population, and so any comparisons between veterans and non-veterans are likely to yield biased estimates of the effect of service (the so called 'healthy soldier' effect). The most credible empirical work in this realm has used quasi-experimental techniques which avoid such self-selection bias, exploiting exogenous variation provided by conscription lotteries (Angrist, 1990), or variation in service obligations between birth cohorts (Angrist \& Krueger, 1994; Imbens \& Van der Klaauw, 1995), or errors in administration of selection rules (Angrist, 1998).

Our approach is to exploit very large differences between birth cohorts in probability of service. Over 90\% of Australian men born in the early 1920s served in WW2. This percentage was close to zero for those born in the late 1920s. The number of Australians who served in other wars in the following decades was much smaller. ${ }^{3}$ Our adopted instrumental variable approach is similar to the one used by Imbens and van der Klaauw (1995). A feature of our analysis is a novel visual depiction of the variation which identifies the estimates, for which we draw on the Frisch-Waugh theorem.

Whilst data availability is a major challenge for such a study, we draw on several sources. First-stage data are drawn from historical personnel records, combined with estimated population counts for each year of birth. The second stage data are drawn from the 1966 Australian Census. This is the earliest Census from which the required data are available.

We consider effects on major life outcomes, specifically employment, government pension receipt, housing, marital status and education. ${ }^{4}$ Our major focus is employment, which may

\footnotetext{
${ }^{3}$ Between the WW2 and Vietnam War eras, the largest contingent of Australians deployed to war was the 17,000 men who served in Korea. This is equal to around $1.7 \%$ of the number who served in the WW2 era.

${ }^{4}$ We would like to also study effects on earnings and health, but we are not presently aware of any appropriate available data.
} 
be affected by service through several mechanisms. It may be negatively influenced by the (mental and physical) health effects of military service, particularly amongst those who saw combat. Employment may be influenced positively or negatively depending on the value placed on military experience in the civilian labour market. Public policy may also affect employment through the incentives created by veterans' compensation schemes; as well as by prioritisation of veterans in public sector recruitment; and indirectly through education benefits.

We find a significant negative effect on employment, and a corresponding (but smaller) positive effect on pension receipt. At first glance the magnitude of these effects appears small (less than 1 percentage point). But we suggest that these effects are not small, given a very strong labour market in 1966, and given the relatively small proportion (about $1 / 6^{\text {th }}$ ) of servicemen who saw combat. We also find a positive effect on home ownership, likely due to veterans' housing assistance, and a positive effect on the likelihood of being divorced or permanently separated.

The remainder of the paper is structured as follows: Section 2 presents a detailed discussion of the nature of service for Australians. Sections 3 and 4 outline methods and data respectively. Section 5 presents the main results, for labour market outcomes, marital status and housing. Section 6 presents a novel visual depiction of the identifying variation which underlies the estimates, drawing on the Frisch-Waugh Theorem. Section 7 concludes.

\section{The recruitment, service and compensation of Australian Servicemen}

\section{Recruitment and training}

World War Two was the first occasion Australians were conscripted into active wartime service. Compulsory military training existed during 1911-29 but only volunteers were enlisted into active service in World War One, serving overseas as the Australian Imperial Force (Ville and Siminski 2011). On the outbreak of war in 1939, a second Australian Imperial Force of volunteers was raised to fight overseas. At the beginning of 1940, compulsory training was resumed. Unmarried men aged 21 were drafted for three months of 
training and then required to serve for three months (Dennis et al. 2008). The conscription coverage gradually broadened over the first two years of the war, eventually being fixed at 18-45 for single men and 18-35 for married men (Ville and Siminski 2011). Initially, conscripts were only required to serve in Australia, along with New Guinea and adjacent islands. In 1942, as the war in south-east Asia came closer to Australian shores, conscripts could be expected to serve in territories in the 'South West Pacific Zone' which included Indonesia, the Philippines, and Japanese-held islands south of the equator. The Australian Army formed the majority of the defence force, with 728,000 enlisted (Robertson 1981, p64), compared with the Royal Australian Air Force, with over 200,000 recruits and the Royal Australian Navy with 37000 recruits (Beaumont 2001, pp. 147, 181).

Training began in Australia with three months of basic fitness, discipline, and weapon handling. Shortages of weapons and ammunition initially constrained some of these activities. The strict discipline and dehumanising attitudes typical of army acculturation were confirmed by the evidence of recruits. Later cohorts, from December 1942, were given more extensive jungle training for the Pacific war through four 'severe' weeks at the Jungle Warfare Training Centre at Canundra in Queensland (Johnston, 1996, 68). On entering active service, recruits were given regular operations training which, in the view of some servicemen, was very repetitive and of limited value preparing soldiers for real combat situations (Beaumont 2001; Johnston, 1996, 68).

\section{Active Service}

Over half a million (550 000) Australians went on active service overseas, about one in 12 of the population (Beaumont 1996, xx). Their experience of service was highly variable. Only a fraction of recruits were in front line activities that were likely to expose them directly to battle. Some Australians served in units alongside fellow countrymen others, especially in the RAAF, were part of a broader British Commonwealth force. While many Australians served in New Guinea and nearby Pacific islands, others found themselves in a variety of locations in Europe and the Middle East, which exposed them to quite different forms of engagement. The early campaigns in the Middle East were conducted on flat terrain, with aircraft and artillery bombardments regularly experienced (Gullett, 1984). The Pacific saw the majority of combat in heavy jungle, involving close fighting in small groups where the front lines were often inaccessible to larger specialist weapons. Fighting in the Pacific also comprised short 
and intense engagement, compared with the drawn out battles of attrition in the Middle East (Long 1973).

Around 27000 Australians were killed in battle or died from wounds or in prison of war camps (Beaumont, 1996, xx). A further 12000 died in training or in non-combat situations while on service. Compared with Britain and America, Australia had a high turnover of soldiers. By April 1945, due to death, injury, and discharge, only 1359 of the 52243 men in the 6th, 7th and 9th Divisions of the AIF remained in service since 1940 (Johnston 1996b, p55). If the length of service plays a key role in the long term consequences of military service, the effects may have been less than experienced by other nations.

\section{Workforce Compensation}

Wartime service impacted upon an individual's workforce opportunities and capabilities. By being removed from the civilian workforce, the servicemen missed out on a period of work experience and/or education and training, which could impact on their lifetime earnings and employability. In addition, the physical or psychological damage caused by service could further damage employability. It might be argued that offsetting these disadvantages, to some degree, were the training, discipline, and teamwork skills that formed part of the military experience.

Repatriation policy in Australia, as elsewhere, recognised that the net effect of wartime service on future employment was probably negative. Compensation policies took several forms. The main compensatory payments of interest, dating back to World War One, were the disability payment (historically called the war pension) along with service pensions paid to veterans on the grounds of age, permanent incapacity to work or total blindness (DVA 2003). Disability payments were based on level of incapacity. Most countries, including Britain, used deciles working down from 100\%. For Australia, any incapacity deemed below 10 percent was considered slight enough to warrant no compensation. Britain was slightly more stringent, with anything below 20 percent receiving no compensation (Garton 1996, p99). Since the Repatriation Act 1920, there is also a special rate of disability pension for those who are totally and permanently incapacitated (TPI), which paid above the normal pension (DVA 2003). 
Pension eligibility fell into two categories: those with or without operational service. Operational service included any service outside Australia, and domestic service which incurred danger from hostile forces (DVA 2003). Operational service had no effect on the range or level of compensation, but determined the standard of proof that would be applied. Disability pension claims by Veterans with operational service have effectively been assessed under a 'reverse-criminal' standard of proof since 1943. (DVA 2003, p85). Under this standard of proof, responsibility lay with the Department of Repatriation to prove that a veteran's injury/disability was not a result of military service. Garton (1996, p. 99) notes that Australia supported 70,000 more pensioners than Canada, which had a greater number of returned men. This may be attributed to these liberal provisions. For the TPI pension, a veteran had to have been an ex-prisoner of war, or have qualifying service and aged 70 years of over, or have a disability rate of $100 \%$ or over (DVA 2003).

One of the new initiatives for the World War Two veterans was the Commonwealth Rehabilitation Training Scheme (CRTS). This was intended to equip and prepare returned servicemen and women with the skills and qualifications to help them re-enter the labour market at the end of the conflict (Garton 1996, pp. 81, 98-9). The CRTS provided them with the opportunity to undertake university education or enter technical education/apprenticeships by paying a living allowance and the cost of fees, tools of trade, and books (Lloyd and Rees 1994). In addition to the CRTS and liberal pension offerings, servicemen returned to a period of post war reconstruction, increased economic activity, and high levels of growth in employment and incomes (Garton 1996). Some servicemen may have been incentivized to the disability pension rather than to work, given the liberal standard of proof. Conversely, the period of increased economic activity and job opportunities may have made servicemen less likely to take the pension.

Further assistance into the workforce was embodied in the employment preference policy. Dating back to World War One, the policy sought to ensure that no ex-servicemen were disadvantaged by employers in seeking to return to the workforce. Anecdotal evidence from disgruntled former servicemen suggests this policy was difficult to monitor and enforce. Even in the public service, where government could exercise a more direct influence, returning servicemen often had to work their way up the ladder in competition with younger employees (Garton, 1996, 89-91). 


\section{Housing Benefits}

A severe shortage of housing among discharged servicemen after both world wars motivated a housing benefits policy. Employment disadvantages and absence on service from private dwellings might impact on a veteran's ability to become a home owner. Beginning in 1918, veterans who had been on active overseas service were able to access loans to purchase or build their home on terms preferential to the market including low interest rates, no deposit, extended payment terms, and rent to purchase provisions. Initially, the government had in mind building houses in blocks to sell to veterans. Within a few years this had failed due to the inexperience of the War Services Homes Commissioner and the urgency of housing demand. In its place, applicants could be funded to build their own home or to buy a new or existing one including refinancing mortgages. Such measures continued during and after World War Two: the maximum loan amounts were regularly increased and the scope of the policy was extended to cover the airforce, all nursing services, and spouses (Australian Housing Corporation 1976: part 1, attachments A-G). The United States and Canada had similar schemes although the former's expired in 1956. UK provision was less generous.

Much of the existing literature focusses on the pensions and retraining schemes but the high rate of take up of housing loans is also noteworthy. Between 1944/5 and 1975 there was around 426000 applications for home loans from among 582000 qualifying former servicemen, most of whom served in World War Two. Of these, approximately 268000 servicemen had received grants by 1975, a take up rate of 46 per cent among eligible veterans Australian Housing Corporation 1976: part 2, attachments H-O). The Commonwealth-State Housing Agreement was also established in 1945 to address the general housing shortage. It focussed on rental support and allocated 45 per cent of its budget to defence force veterans. 3 402 veterans received support. The revised 1956 CSHA shifted focus to encourage home ownership through low interest rate loans or subsidised purchase prices with several hundred homes purchased annually by ex-service personnel over the following two decades (Commonwealth-State Housing Agreement). 


\section{Methods}

Our empirical approach exploits between-cohort variation in military participation rates, similarly to Imbens and van der Klaauw (1995). We first wish to estimate the effect of military service $(S)$ on the probability of being employed $(Y)$ for person $i$ in birth cohort $j$ in the following equation:

$Y_{i j}=\beta_{0}+\beta_{1} S_{i j}+\beta_{2} A_{j}+\beta_{3} A_{j}^{2}+\beta_{4} A_{j}^{3}+\varepsilon_{i j}$

where $\beta_{1}$ is the causal parameter of interest, $A_{j}$ is age in years, and $\varepsilon_{i j}$ includes all other individual determinants of employment. Due to the selection process that the military uses for enlistees and potential self-selection, OLS estimation would likely yield biased estimates of $\beta_{1}$, due to correlation between $S_{i j}$ and the error term, $\varepsilon_{i j}$. Even the inclusion of a rich set of control variables is unlikely to fully avoid such omitted variable bias, as some of the determinants of labour market success which may be correlated with military service are unobserved (some potential examples are intelligence and health).

We avoid omitted variable bias by using an instrumental variable strategy. The instrument we use is the overall military participation rate within each one-year birth cohort $\left(\bar{S}_{j}\right)$, which is plausibly exogenous. The first stage equation is therefore:

$S_{i j}=\pi_{0}+\pi_{1} \bar{S}_{j}+\pi_{2} A_{j}+\pi_{3} A_{j}^{2}+\pi_{4} A_{j}^{3}+\epsilon_{i j}$

As discussed by Imbens and van der Klaauw (1995) the predicted value from this equation $\left(\hat{S}_{i j}\right)$ is identical to $\bar{S}_{j}$, because none of the regressors in the equation vary between cohorts. As we discuss in the following section, we obtain population level data for $\bar{S}_{j}$. Therefore, the first stage regression estimates are not subject to sampling error, again following Imbens and van der Klaauw (1995).

The second stage equation is therefore:

$Y_{i j}=\beta_{0}+\beta_{1} \bar{S}_{j}+\beta_{2} A_{j}+\beta_{3} A_{j}^{2}+\beta_{4} A_{j}^{3}+e_{i j}$

This equation can be estimated by OLS. However, $\bar{S}_{j}$ varies only between cohorts, and so it is appropriate to account for potential inter-cohort correlation of the error term. Since the number of birth cohorts is reasonably small in our case, cluster-robust standard errors may 
not be reliable (Angrist and Pischke 2008: p313). Since all regressors vary only between cohorts, we instead adopt a group-means approach (Angrist and Pischke 2008: p313). In this approach, the data are collapsed to the cohort level:

$\bar{Y}_{j}=\beta_{0}+\beta_{1} \bar{S}_{j}+\beta_{2} A_{j}+\beta_{3} A_{j}^{2}+\beta_{4} A_{j}^{3}+e_{j}$

Equation (4) is estimated by GLS with weights proportional to the number of individuals in each cohort so that the point-estimates are identical to OLS estimates of (3) and the standard errors appropriately account for clustering within each cohort.

\section{Data and Descriptive Statistics}

To implement the empirical strategy outlined above, we only require cohort-level data on military participation rates and labour market outcomes for males. Given the historical nature of this study, even such data are not trivial to obtain, and certain assumptions were required.

The study population is the set of males who lived in Australia at the time of World War 2. A cohort is defined by financial year of birth. We chose financial years of birth (rather than calendar years) to match what is available in the second-stage database.

The first- and second-stage data are described in turn below. We then show descriptive statistics, including comparisons of service intensity between cohorts.

\section{First-Stage Data}

For the first-stage, we require military participation rates for males by financial year of birth. The numerators of these proportions are estimated using the World War Two Nominal Roll (World War Two Nominal Roll 2002). The denominators are taken from the 1933 and 1947 Australian Censuses. ${ }^{5}$

\footnotetext{
${ }^{5}$ For parsimony we refer to financial years in shorthand herein. For example, 1900 refers to the 1899-1900 financial year.
} 
We use the Nominal Roll to obtain counts of Australian men who served in the military in the WW2 era, by cohort. The Nominal Roll was created to honour those Australians who served in World War Two. It includes data from service records held by the Department of Defence, as well as data from the Commonwealth War Graves Commission for those who died in service. It includes date of birth, residency, start and end date of service, date of death and prisoner of war status. The records are held by the National Archives of Australia.

These counts are subject to measurement error, for three reasons. First, the Nominal Roll does not record gender. In personal correspondence, DVA advised that the Nominal Roll includes an estimated 60,000 women overall (or 5.88 percent of the total). Without further information on the age distribution of those women, we assume that this proportion is constant across cohorts, and we deflate the counts accordingly. Second, there are multiple records in the Nominal Roll for some individuals who had a break in service. We have been advised that the extent of such duplication has never been estimated, on the basis that many such duplicates likely contain minor changes in personal details, due either to recording inaccuracy or to enlistees' strategic reasons. Finally, 108,320 records (approximately 10\%) are missing DOB. We assume that the upward bias due to duplicate records approximately offsets the downward bias due to missing DOB. A further limitation of the Nominal Roll is that it does not flag those who were deployed.

The denominator of the participation rates (i.e. counts of men by year of birth) is sourced from published data from the 1933 and 1947 Censuses. The 1933 Census was the last Census prior to WW2 and the 1947 Census was the first one after WW2. We regard both as very good proxies for the size of the WW2-era male population by year of birth, because migration was very low during this era (Philips et al. 2010; Hatton and Withers, 2015, p352). ${ }^{6}$ When constructing the proportions using 1947 Census counts, we exclude men who died during WW2, since they are obviously excluded from the denominators as well.

\footnotetext{
${ }^{6}$ Given that the 1933 Census was taken six years before the outbreak of the War, we considered adjustments for population change using historical population estimates, which are available in 5-year age brackets at June 30 of each year (ANS, 2014). But the size of each relevant 5-year birth cohort barely changed between 1933 and 1938 (usually by less than $1 \%$ ), and so adjustments were deemed unnecessary.
} 
Figure 1 shows the resulting estimated WW2 participation rates for men born from 18991900 to 1939-40, using the 1933 and 1947 Census counts, respectively, as well as the average of the two. ${ }^{7}$ Encouragingly, these proportions are not sensitive to the choice of 1933 or 1947 Census counts in the denominators. Figure 1 also shows much variation in participation between birth cohorts, with a significant drop for those cohorts born after 1924, going from 86 to 2 percent in four years. This is due to the conflict coming to an end, and the subsequent reduced need for Australian manpower.

The first-stage database thus consists of 41 observations, one for each year of birth between 1899-1900 and 1939-1940. These birth cohorts include approximately 2.3 million Australian men at the end of WW2. This data window was chosen to be centred around the 1919-1920 birth year, where WW2 participation rates were the highest. However, the preferred version of the analysis uses smaller windows of birth cohorts for some outcomes, for reasons that are discussed below. Sensitivity to the choice of data-windows is discussed in detail and numerous robustness tests are conducted.

The upper panel of Table 1 shows descriptive statistics from the first stage database. Across the 41 birth cohorts, 39.5\% of men served in the World War 2 era. Amongst those who did serve, 3.8\% died in service, 3.0\% were captured as Prisoners of War, and the average length of service was 3.44 years.

\section{Second-Stage Data}

The data used in the second stage regressions are from the 1966 Australian Census of Population and Housing. We obtained frequency tabulations from the full database, for which $100 \%$ of the Australian population was in scope. Men who reported arriving in Australia after WW2 were excluded from the tabulations, leaving 2,081,453 respondent males born between 1899-1900 and 1939-1940. Several frequency tabulations were obtained, each by single year of age, for a range of outcome variables including labour market status, marital status, housing outcomes, and educational attainment.

\footnotetext{
${ }^{7}$ The proportions estimated using 1933 denominators are assumed to be zero for cohorts born after the 1933 Census date. These males were aged 12 years or less when WW2 ended.
} 
The lower panel of Table 1 shows descriptive statistics for the second stage database. It shows that $91.7 \%$ of men in these cohorts were employed (this increases to $94.9 \%$ when men aged 60 or more are excluded). The proportion unemployed was very low at $0.9 \%$, while the remainder (7.4\%) were not in the labour force. Of those not in the labour force, the majority were self-categorised as pensioners (3.9\%). Large majorities of these men were married (81.5\%) and owned their own home (70.4\%). Only a small minority completed tertiary education (6.6\%).

Our empirical approach relies on the assumption that a cubic function of age adequately controls for all non-service factors that vary between cohorts. We scrutinise this assumption for key outcome variables in Figure 3. The upper-left panel shows the proportion of men classified as employed by birth year. This graph shows little variation, except for in the oldest cohorts. In particular, there appears to be a large discontinuity at age 65 (i.e. between the 1900-01 and 1901-02 cohorts), and a smaller discontinuity at age 60 (i.e. between the 190506 and 1906-07 cohorts). This is not surprising, because eligibility for the civilian age pension commenced at age 65, whilst eligibility for the (military) service pension commenced at age 60. A second feature of this plot is that employment rates are very high for cohorts that have not reached retirement age. The employment to population ratio is $94.9 \%$ amongst men born between 1906-07 and 1939-40. Another feature is that the employment rate varies extremely smoothly between cohorts. Indeed, a cubic function of age explains $98.8 \%$ of the variation in employment rates between cohorts, after excluding those aged 60 or more. ${ }^{8}$ Given these discontinuities in employment rates at ages 65 and 60 , we exclude cohorts older than 60 from the analysis of labour market outcomes. The rationale is that any smooth function of age is not an adequate control for non-service differences between cohorts.

The upper right panel of Figure 3 shows a similar scatterplot, for the proportion of men who were married. This proportion is high for every birth cohort and it varies smoothly between them. However, the proportion dips sharply for the youngest birth cohorts, who were aged in their late-20s at the Census date. A cubic function of age explains $90.4 \%$ of the variation in marriage rates between cohorts. But this increases considerably to $96.4 \%$ if the youngest three cohorts are excluded. We exclude the youngest three cohorts from the analysis of marital outcomes.

\footnotetext{
${ }^{8}$ This proportion is considerably lower (90.9\%) if the older birth cohorts are included.
} 
The lower left panel of Figure 3 shows the scatterplot for home ownership. Again, the variation between cohorts appears very smooth, this time with no evidence of discontinuities or outliers. A cubic function of age explains $99.3 \%$ of the variation across the full set of birth cohorts. We use the full set of cohorts in the analysis of housing outcomes.

The lower right panel of Figure 3 shows the scatterplot for completion of tertiary education. The variation between cohorts here is the least smooth amongst the four outcome variables shown here. A cubic function of age still explains $94.9 \%$ of the variation between cohorts. Nevertheless, visually, the series appears to follow a path that systematically trends upwards and downwards at various sections of the birth cohort range. On this basis, it does not appear appropriate to use our adopted empirical approach to study schooling outcomes.

\section{Intensity of Service by Year of Birth}

Our empirical approach assumes that the effect of service is constant across birth cohorts. We scrutinise this assumption here, by considering variation in service intensity between cohorts on available indicators. In particular, we show that younger cohorts who entered just before the end of the War did not have the same intensity of service as did older birth cohorts. We then discuss two strategies to navigate this issue.

Three proxies were constructed from Nominal Roll data. These are death rates, rates of capture as Prisoner of War, and mean length of service. ${ }^{9}$ Figure 2 shows each of these by birth cohort. On each of these indicators, the 1918-1919 birth cohort appears to have had the most intense form of service, with a 5.7\% death rate, a 5.2\% POW rate and a 3.7 year average length of service. However, these do not differ greatly from most older cohorts, nor from the 1920 cohort. The main feature of the graph is that service intensity declines routinely on all three measures from 1921 onwards.

\footnotetext{
${ }^{9}$ Length of service was calculated using the recorded starting date and finishing date for each individual. There are a number of missing entries for the start and end date of service for individuals. Where an individual is missing an end date, but a date of death has been recorded, the date of death is used as the end date of service. Length of service was not able to be calculated for $5 \%$ of records.
} 
Our main strategy to address this issue is to test sensitivity of each result to the exclusion of cohorts born between 1921 and 1927 - i.e. those who served at the end of the war and hence had the lowest service intensity. These sensitivity tests are reported in the main set of results tables. We also ran some additional versions of the analysis where military service is interacted with the service intensity proxies. We ran these for each outcome variable we consider in the main analysis. These interaction terms were not significant at the $5 \%$ level for any outcome when using the preferred birth cohort range. This suggests that the effects do not vary greatly by service intensity. Alternatively, these variables may not be adequate proxies for service intensity.

\section{2SLS Results}

Since the population value of the first stage is known without sampling error, there is no first stage regression output, following Imbens and Van Der Klauw (1995), as discussed above.

\section{Labour Market Outcomes}

Table 2 shows the estimated effects of military service on labour market outcomes, from a series of 2SLS regressions for labour market outcomes. Column (1) shows results from regressions which use the full set of birth cohorts. Results in columns (2), (3) and (4) are from models which include progressively fewer cohorts, each centred around the cohorts which had the highest rates of military service (those born in the early 1920s). Column (5) shows results from models which use the same cohorts as Column (1), except for the 19211927 cohorts. These serve as robustness tests to the exclusion of cohorts which apparently experienced less intense service, as measured by POW rates, death rates and length of service.

Employment is the dependent variable in Panel A. The results in the five columns consistently show evidence of a statistically significant negative effect on employment. The estimated effects seems small - ranging from -0.77 to -1.16 percentage points. The estimate 
in each column is very precisely estimated. That is, the standard errors are very small, despite the small number of observations in these regressions. The R-squared statistics are also unusually high. This is mainly because the cubic function of age explains almost all of the variation in employment. We discuss the identifying variation for these results in more detail in the next section, using visual depictions which refer to the Frisch-Waugh theorem.

Panel B shows results for unemployment. It shows statistically significant, positive effects of service across columns. These are all small, ranging from 0.09 to 0.17 percentage points. Unemployment thus explains only around $10 \%$ of the negative employment effect. This suggests that service must have reduced labour force participation. This is confirmed in Panel $\mathrm{C}$, for which the dependent variable is NILF (not in labour force). Again, the estimates are consistently significant across columns. They range from 0.6 percentage points to 1.4 percentage points.

Panel D shows the estimated effects of service on identifying as a pensioner. Pensioners are a majority subset of those out of the labour force. Once again, the estimates do not vary greatly between columns and are statistically significant in each case. They show that military service increased the probability of identifying as a pensioner by an estimated 0.41 to 0.65 percentage points. This is around half the size of the employment effect. Finally, Panel E shows estimated effects on being an inmate of an institution - another subset of NILF. Whilst each point estimate is positive, none is statistically significant.

\section{Marital Outcomes}

Table 3 shows 2SLS estimated effects on marital outcomes. It has the same structure as Table 2, apart from the slightly different set of cohorts included in Columns (1) and (5), as discussed in Section 4. Panel A shows estimated effects on the probability of being married. The results are not conclusive. Columns (1) and (5) suggest that service may have negatively affected the probability of being married, with estimates that are statistically significant at the $10 \%$ level. However, the estimates in the other columns are close to zero and are not statistically significant. 
Despite this, there is evidence that WW2 service increased the probability of being divorced or permanently separated. Panel B of Table 2 shows statistically significant positive effects in four of the five columns. The magnitude of the effects does not vary greatly between columns, ranging from 0.25 to 0.32 percentage points. Panel $\mathrm{C}$ shows results for the likelihood of never being married. It shows no evidence that this probability was affected by service.

\section{Housing Outcomes}

Results for housing outcomes are shown in Table 4, which follows the structure of the previous two tables. It suggests that the effects on housing were substantial. Panel A shows estimated effects on the probability of being a home owner. These are statistically significant in each column, ranging from 1.4 to 2.0 percentage points. Panels B and C show corresponding effects for private and public rental, respectively. These are always negative and significant and they offset the positive home ownership effect.

Panels D and E of Table 4 show results for number of rooms and presence of a television in the household, respectively. The number of rooms is a proxy for housing quality. The results suggest that service increased the quality of veterans' housing, as the estimates are statistically significant in four of the five columns. Since television ownership was not universal in 1966, we treat it as an indicator of economic wellbeing. It is one of few such indicators available in the census data. The results do not suggest that television ownership was affected. Two of the point estimates are negative and three are positive. Only one is statistically significant, and only at the ten percent level.

\section{Visual Depiction of Identifying Variation}

In this section, we graphically illustrate the variation that underlies the estimates presented in the previous section. Those estimates are from regressions which draw on at most 41 observations. These estimates all have very small standard errors. The regressions also have 
very high R-squared statistics. Here we attempt to provide some additional intuition for those results, drawing on the Frisch-Waugh theorem. By doing so, we also make the source of identifying variation more explicit.

The Frisch-Waugh theorem (also known as the Frisch-Waugh-Lovell theorem) provides an intuitive alternative derivation for multiple-regression parameters estimates. Davidson and MacKinnon (1993) provide a detailed discussion of the theorem. In brief, the theorem states that a co-efficient in a multiple regression model can be derived through an alternate three equation process. Consider equation (4), with $\beta_{1}$ estimated by OLS. In the first Frisch-Waugh equation, the explanatory variable of interest (S) is regressed on the other explanatory variables (i.e. the control variables). In our context, the first Frisch-Waugh equation is:

$\bar{S}_{j}=\gamma_{0}+\gamma_{1} A_{j}+\gamma_{2} A_{j}^{2}+\gamma_{3} A_{j}^{3}+u_{j}$

The residual from this regression $\left(\hat{u}_{j}\right)$ is the component of $S$ that is orthogonal to the control variables.

In the second Frisch-Waugh equation, the outcome variable $(\mathrm{Y})$ is regressed on the same set of control variables:

$Y_{j}=\delta_{0}+\delta_{1} A_{j}+\delta_{2} A_{j}^{2}+\delta_{3} A_{j}^{3}+v_{j}$

The residual from this regression $\left(\hat{v}_{j}\right)$ is the component of $\mathrm{Y}$ that is orthogonal to the control variables.

In the third Frisch-Waugh regression, the residuals from the second equation $\left(\hat{v}_{j}\right)$ are regressed on the residuals from the first equation $\left(\hat{u}_{j}\right)$.

$\hat{v}_{j}=\alpha+\beta_{1} \hat{u}_{j}+\mu_{j}$

The simple OLS estimate of $\beta_{1}$ from (7) is identical to the regular estimate in a multiple regression model as per equation (4). This demonstrates that the multiple-regression is equivalent to a simple regression involving the components of two variables which are respectively orthogonal to the control variables.

Panel A in Figure 4 shows a scatter plot of military service rates by year of birth ranging from 1907 to 1937. Superimposed is the set of fitted values from equation (5). It shows that a cubic function of age does not closely fit the scatterplot. The cubic function of age explains $75.7 \%$ 
of the variation. This is the R-squared value from equation (5). The vertical distance between each point in the scatter plot and the cubic fit is the residual for each observation in equation (5). Observations which are above the fit have positive residuals in the first Frisch-Waugh equation, and vice versa. The observations lying within the red ovals in Figure 7 have large negative residuals, whilst those within the green ovals have large positive residuals.

Panel B shows the corresponding scatterplot and fitted values from the second Frisch-Waugh regression, using employment as the outcome variable. The cubic function of age explains nearly all of the variation (the R-squared is 0.991). Again, the vertical distances between each observation and the fit represent the residuals from the second Frisch-Waugh regression, when employment is the outcome variable. The colour of the ovals corresponds to the residuals of the first Frisch-Waugh regression. Those in the green ovals have positive residuals in Panel A; but almost all of them have negative residuals in Panel B. Likewise, those in the red ovals had negative residuals in Panel A, and nearly all of the corresponding observations have positive residuals in Panel B. These graphs demonstrate the residual variation that is driving the small negative (and yet highly statistically significant) estimates that were found in Table 1.

Panel C depicts the scatter plot and fitted values which correspond to the third Frisch-Waugh regression. Even though the cubic function of age explains almost all of the variation in employment rates between cohorts, it is clear that the remaining variation in employment rates is strongly correlated with the corresponding residual variation in military service rates. The R-squared for the third Frisch-Waugh regression is 0.628 . This means that after age is 'partialled-out', differences in military service rates explain $62.8 \%$ of between-cohort variation in employment.

\section{Conclusion}

Our analysis suggests that WW2-era military service had a negative effect on the likelihood of being employed in 1966. The effect size is around one percentage point, which appears small at first glance. This suggests that most veterans were effectively reintegrated into the civilian labour market. However, only around half of servicemen were deployed and of those deployed, around one-third saw combat. If one assumes that only those who saw combat were 
affected, the implied effect size for those men is 6 percentage points. Further, the employment data were collected when these men were in their prime working age at a time when the labour market was very strong. For men in these birth cohorts, the employment to population ratio was around 95\% in 1966. The negative employment effect occurred despite government policy to prioritise veterans in public sector recruitment. On further inspection, most of the employment effect is characterised by men leaving the labour force, although there is evidence of a small elevated unemployment rate as well.

The employment effect is accompanied by an increase in the likelihood of identifying as a pensioner. The magnitude of the increase in pensioner status is only half that of the employment effect. This suggests that veterans' compensation reached only some of the men whose employment was affected by service.

The effects on marital status are also relatively modest. No effect was found on the overall probability of being married, nor on the likelihood of having never married. However, there is evidence of an increased probability of being divorced or permanently separated. Again the magnitude seems small (0.3 percentage points). But the mean proportion of men who identified as divorced or separated is also small at 3.9 percentage points. This result may hence be suggestive of relationship problems more broadly.

The largest effects are found for housing. In particular, military service increased the probability of home ownership by around 1.4 to 2.0 percentage points. Given the generous support given to veterans to assist with home purchase, it is perhaps surprising that the effects are not larger.

The results lend some support to the conclusions of historians - that Australian servicemen fared worse in the labour market (Garton) and that family life was likely to be disrupted (Damousi). The results also have implications for studying the precise effects of service in the many other nations that participated in World War Two. The only work to date using quasi-experimental methodology is for the United States which suggests comparable outcomes - lower earnings (Angrist and Krueger 1994) and greater home ownership (Fetter 2013). There may, however, prove to have been more substantial consequences for some of the other major combatants. Britain appears to have had less generous pension and housing schemes and longer average service; Canada had fewer pensioners as a result of a tougher service qualification for compensation. While each war has provided a somewhat different 
service experience, a closer understanding of the full effects of military service is an important policy question that is informed by historical evidence and analysis.

\section{References}

Angrist, J (1990) "Lifetime Earnings and the Vietnam Era Draft Lottery: Evidence from Social Security Administrative Records”, The American Economic Review, vol.80, no.3, pp.316-336

Angrist, J. (1998) “Estimating the Labour Market Impact of Voluntary Military Service using Social Security Data”, Econometrica, vol.66, no.2, pp.249-288

Angrist, J. and Krueger, A. (1994) "Why Do World War II Veterans Earn More Than Nonveterans”, Journal of Labor Economics, vol.12, no.1, pp.74-97

Angrist, J. and Chen, S. (2010) "Schooling and the Vietnam-Era GI Bill: Evidence from the Draft Lottery”, American Economic Journal: Applied Economics, vol.3, pp.96-118

Ashburner, J (1946) "Psychology in the Australian Army”, The Medical Journal of Australia, vol.2, pp.86-92

Australian Bureau of Statistics (ABS) (2014) Australian Historical Population Statistics, ABS Cat. No. 3105.0.65.001.

Australian Housing Corporation (1976) Defence Service Homes Scheme: Its Nature, History and Operations, Canberra : Australian Government Publishing Service.

Australian Institute of Health and Welfare (AIHW) (2006) Mortality over the twentieth century in Australia: Trends and patterns in major causes of death, Canberra.

Autor, D., Duggan, M. and Lyle, D. 'Battle Scars? (2011) The Puzzling Decline in Employment and Rise in Disability Receipt among Vietnam Era Veterans', American Economic Review: Papers and Proceedings, 101: 339-344.

Bauer, T., Bender, S., Paloyo, A. and Schimdt, C. (2012) 'Evaluating the Labour-Market Effects of Compulsory Military Service’, European Economic Review, vol.56 pp.814829 
Beaumont, J (1996) Australia’s War 1939-45, Allen and Unwin

Beaumont, J (2001) Australian Defence: Sources and Statistics, Oxford University Press, South Melbourne

Bouffard, L. (2003) "Examining the Relationship between military service and criminal behavior during the Vietnam era: A Research note”, Criminology, vol.41 no.2 pp.491520

Chen, S. and Angrist, J. (2010) "Did Vietnam veterans get sicker in the 1990s? The complicated effects of military service on self-reported health”, Journal of Public Economics, vol.94 no.11 pp.824-837

Commonwealth Bureau of Census and Statistics (1966) Census of Population and Housing, 30 June 1966 Volume 1: Single Characteristics, ABS, Canberra

'The Commonwealth-State Housing Agreement'.

http://www.aph.gov.au/About_Parliament/Parliamentary_Departments/Parliamentary _Library/Publications_Archive/archive/StateHouseAgree Accessed 14 December 2015.

Dennis, P., Grey, J., Morris, E. and Prior, R. (2008) The Oxford Companion to Australian Military History, Oxford University Press, South Melbourne

Department of Veteran Affairs (DVA) (2003) The Report of the Review of Veteran's Entitlements, Chapter 5: Types of Repatriation Benefits, DVA, Canberra.

Department of Veteran Affairs (DVA) (2013), Veterans Health Cards, accessed 13/5/2014 http://www.dva.gov.au/benefitsAndServices/health_cards/Pages/index.aspx

Family Law Court (2004) Family Law Principles: No Fault Divorce, accessed 5 November 2014

http://www.familylawcourts.gov.au/wps/wcm/connect/FLC/Home/Family+Law+Prin ciples/No+fault+divorce/

Fetter, D. (2013) 'How Do Mortgage Subsidies Affect Home Ownership? Evidence from the Mid-Century GI Bills’ American Economic Journal: Economic Policy, 5(2): 111-147. 
Friedman, M. (1967) 'Why not a Volunteer Army?’ New Individualist Review, Spring 1967: 3-9.

Galliani, S., Rossi, M. and Schargrodsky, E. (2011) "Conscription and crime: Evidence from the Argentine Draft Lottery”, American Economic Review: Applied Economics, vol.3, no. 2 pp.119-136

Garton, S (1996) The Cost of War: Australia’s Return,

Goldberg, J., Richards, M., Anderson, R and Rodin, M. (1991) “Alcohol consumption in men exposed to the military draft lottery: A natural experiment”, Journal of Substance Abuse, vol.3 no.3, pp.307-313

Grey, J. (2008) A Military History of Australia, Cambridge University Press, Port Melbourne

Gullett, H (1984) Not as a Duty Only: An Infantryman’s War, Melbourne University Press, Melbourne

Hatton, T. and Withers, G. (2015) “The Labour Market”, in Ville, S. and Withers, G. (eds), The Cambridge Economic History of Australia, Cambridge University Press, Port Melbourne, pp.351-372

Imbens, G., and van der Klaauw, W., (1995) "Evaluating the cost of conscription in the Netherlands”, Journal of Business and Economic Statistics, vol.13, no.2, pp.207-215

Johnston, M (1996a) “The Civilians Who Joined Up”, Journal of the Australian War Memorial, Issue 29

Johnston, M (1996b) At the Front Line: Experiences of Australian Soldiers in World War II, Oxford University Press, Oakleigh Melbourne.

Johnston D, Shields M, Siminski P Long-Term Health Effects of Vietnam-Era Military Service: A Quasi-Experiment using Australian Conscription Lotteries IZA Discussion Paper No. 8852.

Lloyd, C. and Rees, J. (1994) The Last Shilling: A History of Repatriation in Australia, Melbourne University Press, Carlton Victoria 
Long, G (1973) The Six Years War: A Concise History of Australia in the 1939-1945 War, Australian War Memorial and the Australian Government Publishing Service, Canberra

Marwick, A (1974) War and Social Change in the Twentieth Century, Macmillan Press, London

Odgers, G (1999) 100 Years of Australians at War, Lansdowne Press, Sydney

Oi, W (1967) “The Economic Cost of the Draft”, The American Economic Review, vol.57, no.2 pp.39-62

Phillips, J., Klapdor, M \& Simon-Davies, J. (2010) Migration to Australia since federation: A Guide to the statistics, Department of Parliamentary Services

Robertson, J (1981) Australia at War: 1939-1945, Heinemann, Melbourne

The Sax Institute (2014) 45 and Up Survey: Questionnaires, accessed 14 May 2014

<https://www.saxinstitute.org.au/our-work/45-up-study/questionnaires/>

Siminski, P. (2013) “Employment effects of army service and veterans' compensation: Evidence from the Australian Vietnam-era Conscription Lotteries”, The Review of Economics and Statistics, vol.95 no.1, p87-97

Siminski, P., and Ville, S., (2012) "I was only nineteen, 45 years ago: What can we learn from Australia's conscription lotteries?”, The Economic Record, vol.88, no.282, pp.351-371

Ville, S. and Siminski, P. (2011) “A fair and equitable method of recruitment? Conscription by ballot into the Australian army during the Vietnam war", Australian Economic History Review, vol.51, no.3, pp/277-296

World War Two Nominal Roll (2002) About this Nominal Roll, accessed 15/4/2014

$<\underline{\text { http://www.ww2roll.gov.au/About.aspx }>}$ 


\section{$\underline{\text { A: First Stage Data }}$}

Military Service

Proportion of Servicemen Died

0.038

Proportion of Servicemen Prisoners of War

0.030

Years of Service amongst Servicemen

Number of birth cohorts

B: Second Stage Data

Employed

Unemployed

Not in Labour Force

0.074

Pensioner

0.039

Inmate of Institution

0.008

Married

0.815

Permanently Separated or Divorced

Never Married

0.126

Home Owner

0.704

Public Renter

0.047

Private Renter

Number of Rooms

Has Television

Completed Tertiary Education

0.066

Completed High School

0.133

Number of Men

2,108,736

Number of Birth Cohorts 


\begin{tabular}{|c|c|c|c|c|c|}
\hline Birth cohorts included & $\begin{array}{c}(1) \\
1907-1940\end{array}$ & $\begin{array}{c}(2) \\
1907-1937\end{array}$ & $\begin{array}{c}(3) \\
1910-1934\end{array}$ & $\begin{array}{c}(4) \\
1912-1932\end{array}$ & $\begin{array}{c}(5) \\
1907-1940 \\
\text { (excl. 1921- } \\
1927)\end{array}$ \\
\hline $\begin{array}{l}\text { Estimate } \\
\text { Standard Error } \\
N \\
R^{2}\end{array}$ & $\begin{array}{c}-0.0116^{* * *} \\
(0.0020) \\
34 \\
0.994\end{array}$ & $\begin{array}{c}-0.0108^{* * *} \\
(0.0016) \\
31 \\
0.996\end{array}$ & $\begin{array}{c}\text { A: Employed } \\
-0.0090^{* * *} \\
(0.0019) \\
25 \\
0.994\end{array}$ & $\begin{array}{c}-0.0077^{* * *} \\
(0.0018) \\
21 \\
0.995\end{array}$ & $\begin{array}{c}-0.0113^{* * *} \\
(0.0032) \\
27 \\
0.995\end{array}$ \\
\hline $\begin{array}{l}\text { Estimate } \\
\text { Standard Error } \\
N \\
R^{2}\end{array}$ & $\begin{array}{c}0.0012^{* * *} \\
(0.0004) \\
34 \\
0.559\end{array}$ & $\begin{array}{c}0.0012^{* * *} \\
(0.0004) \\
31 \\
0.564\end{array}$ & $\begin{array}{c}\text { B: Unemployed } \\
0.0015^{* * *} \\
(0.0005) \\
25 \\
0.561\end{array}$ & $\begin{array}{c}0.0017^{* *} \\
(0.0007) \\
21 \\
0.474\end{array}$ & $\begin{array}{c}0.0009^{*} \\
(0.0005) \\
27 \\
0.675\end{array}$ \\
\hline $\begin{array}{l}\text { Estimate } \\
\text { Standard Error } \\
N \\
R^{2}\end{array}$ & $\begin{array}{c}0.0104^{* * *} \\
(0.0019) \\
34 \\
0.995\end{array}$ & $\begin{array}{c}0.0097^{* * *} \\
(0.0016) \\
31 \\
0.997\end{array}$ & $\begin{array}{c}\text { C: NILF } \\
0.0075^{* * *} \\
(0.0017) \\
25 \\
0.995\end{array}$ & $\begin{array}{c}0.0060^{* * *} \\
(0.0016) \\
21 \\
0.996\end{array}$ & $\begin{array}{c}0.0104^{* * *} \\
(0.0032) \\
27 \\
0.995\end{array}$ \\
\hline $\begin{array}{l}\text { Estimate } \\
\text { Standard Error } \\
N \\
R^{2}\end{array}$ & $\begin{array}{c}0.0061^{* * *} \\
(0.0009) \\
34 \\
0.996\end{array}$ & $\begin{array}{c}0.0058^{* * *} \\
(0.0009) \\
31 \\
0.997\end{array}$ & $\begin{array}{c}\text { D: Pensioner } \\
0.0046^{* * *} \\
(0.0009) \\
25 \\
0.996\end{array}$ & $\begin{array}{c}0.0041^{* * *} \\
(0.0008) \\
21 \\
0.997\end{array}$ & $\begin{array}{c}0.0065^{* * *} \\
(0.0015) \\
27 \\
0.996\end{array}$ \\
\hline $\begin{array}{l}\text { Estimate } \\
\text { Standard Error } \\
N \\
R^{2}\end{array}$ & $\begin{array}{c}0.0008 \\
(0.0005) \\
34 \\
0.782\end{array}$ & $\begin{array}{c}0.0006 \\
(0.0005) \\
31 \\
0.848\end{array}$ & $\begin{array}{c}\text { E: Inmate } \\
0.0009 \\
(0.0006) \\
25 \\
0.789\end{array}$ & $\begin{array}{c}0.0004 \\
(0.0006) \\
21 \\
0.632\end{array}$ & $\begin{array}{c}0.0010 \\
(0.0009) \\
27 \\
0.791\end{array}$ \\
\hline
\end{tabular}

Notes: This table shows 2SLS estimated effects of WW2 service on labour market outcomes measured in 1966. Each regression includes a cubic function of age as per equation (4). ${ }^{*} p<0.10,{ }^{* *} p<0.05,{ }^{* * *} p<0.01$ 


\begin{tabular}{|c|c|c|c|c|c|}
\hline Birth cohorts included & $\begin{array}{c}(1) \\
1900-1937\end{array}$ & $\begin{array}{c}(2) \\
1907-1937\end{array}$ & $\begin{array}{c}(3) \\
1910-1934\end{array}$ & $\begin{array}{c}(4) \\
1912-1932\end{array}$ & $\begin{array}{c}(5) \\
1900-1937 \\
\text { (excl. 1921- } \\
1927)\end{array}$ \\
\hline & \multicolumn{5}{|c|}{ A: Married } \\
\hline Estimate & $-0.0071^{*}$ & -0.0018 & 0.0013 & -0.0024 & $-0.0101^{*}$ \\
\hline Standard Error & $(0.0036)$ & $(0.0038)$ & $(0.0038)$ & $(0.0048)$ & $(0.0050)$ \\
\hline$N$ & 38 & 31 & 25 & 21 & 31 \\
\hline \multirow[t]{2}{*}{$R^{2}$} & 0.968 & 0.947 & 0.912 & 0.872 & 0.966 \\
\hline & \multicolumn{5}{|c|}{ B: Divorced or Permanently Separated } \\
\hline Estimate & $0.0032^{* * *}$ & $0.0025^{* *}$ & $0.0028^{*}$ & 0.0027 & $0.0031^{* *}$ \\
\hline Standard Error & $(0.0009)$ & $(0.0011)$ & $(0.0014)$ & $(0.0018)$ & $(0.0011)$ \\
\hline$N$ & 38 & 31 & 25 & 21 & 31 \\
\hline \multirow[t]{2}{*}{$R^{2}$} & 0.986 & 0.987 & 0.980 & 0.977 & 0.989 \\
\hline & \multicolumn{5}{|c|}{$\underline{\text { C: Never Married }}$} \\
\hline Estimate & 0.0004 & -0.0021 & -0.0054 & -0.0013 & 0.0030 \\
\hline Standard Error & (0.0029) & $(0.0036)$ & $(0.0036)$ & $(0.0043)$ & $(0.0040)$ \\
\hline$N$ & 38 & 31 & 25 & 21 & 31 \\
\hline$R^{2}$ & 0.985 & 0.987 & 0.984 & 0.982 & 0.988 \\
\hline
\end{tabular}

Notes: This table shows 2SLS estimated effects of WW2 service on marital outcomes measured in 1966. Each regression includes a cubic function of age as per equation (4). ${ }^{*} p<0.10,{ }^{* *} p<0.05,{ }^{* * *} p<0.01$ 


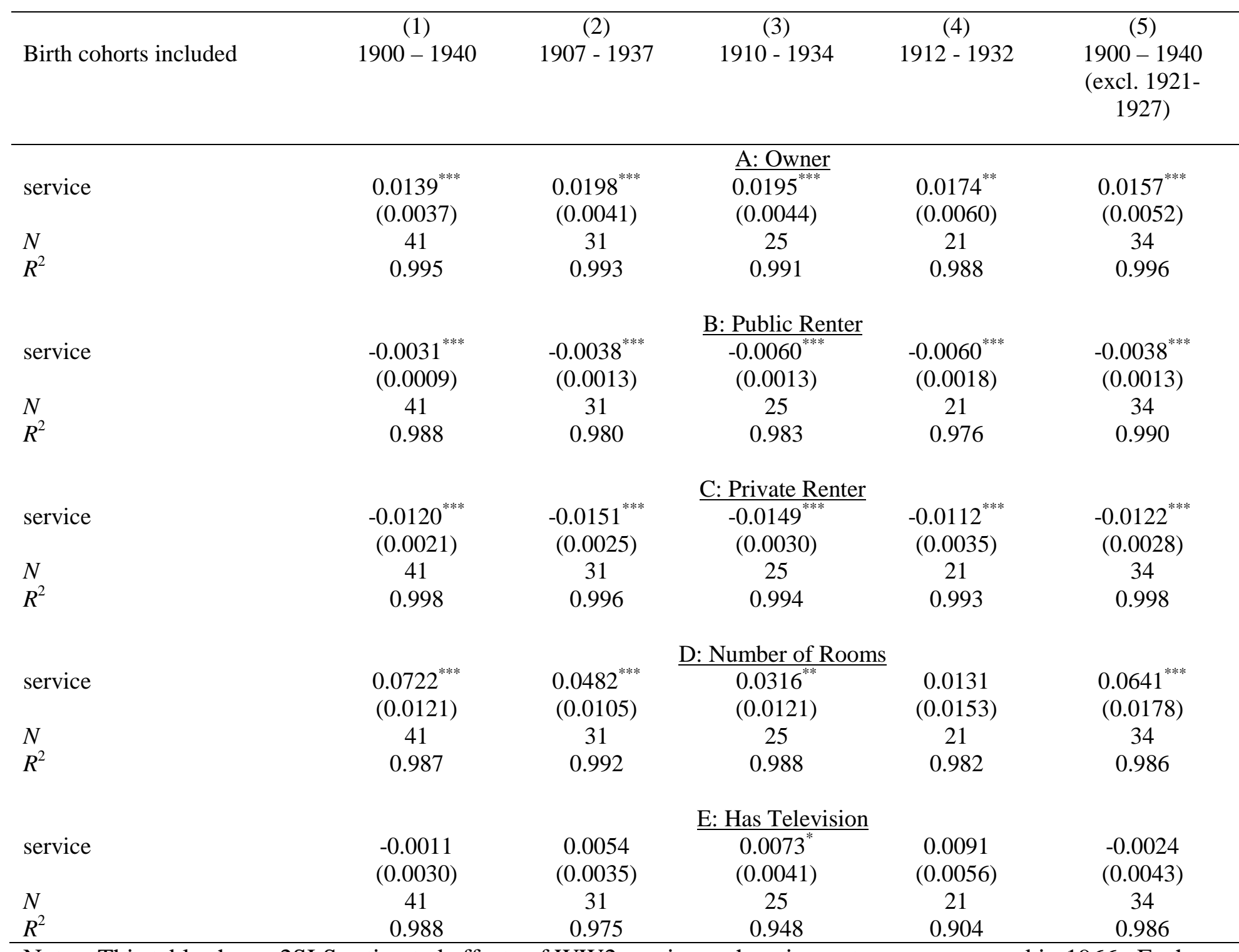

Notes: This table shows 2SLS estimated effects of WW2 service on housing outcomes measured in 1966. Each regression includes a cubic function of age as per equation (4). ${ }^{*} p<0.10,{ }^{* *} p<0.05,{ }^{* * *} p<0.01$ 


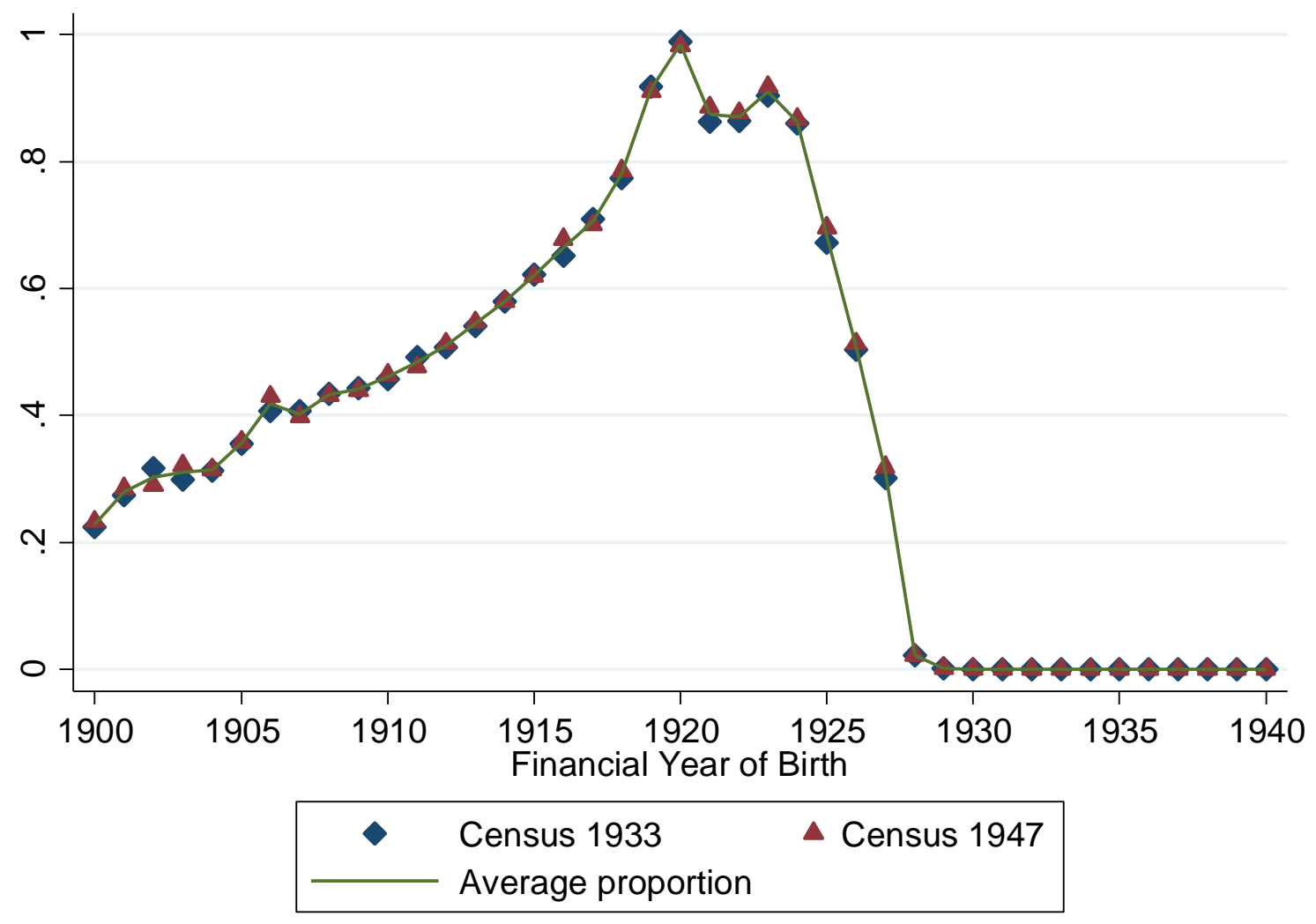

Notes: Numerators calculated from the WW2 Nominal Roll after adjusting for gender composition. Denominators are taken from the 1933 and 1947 Censuses. For parsimony, 1900 refers to the 1899-1900 financial year birth-cohort, similarly for the other years. See text for details. 


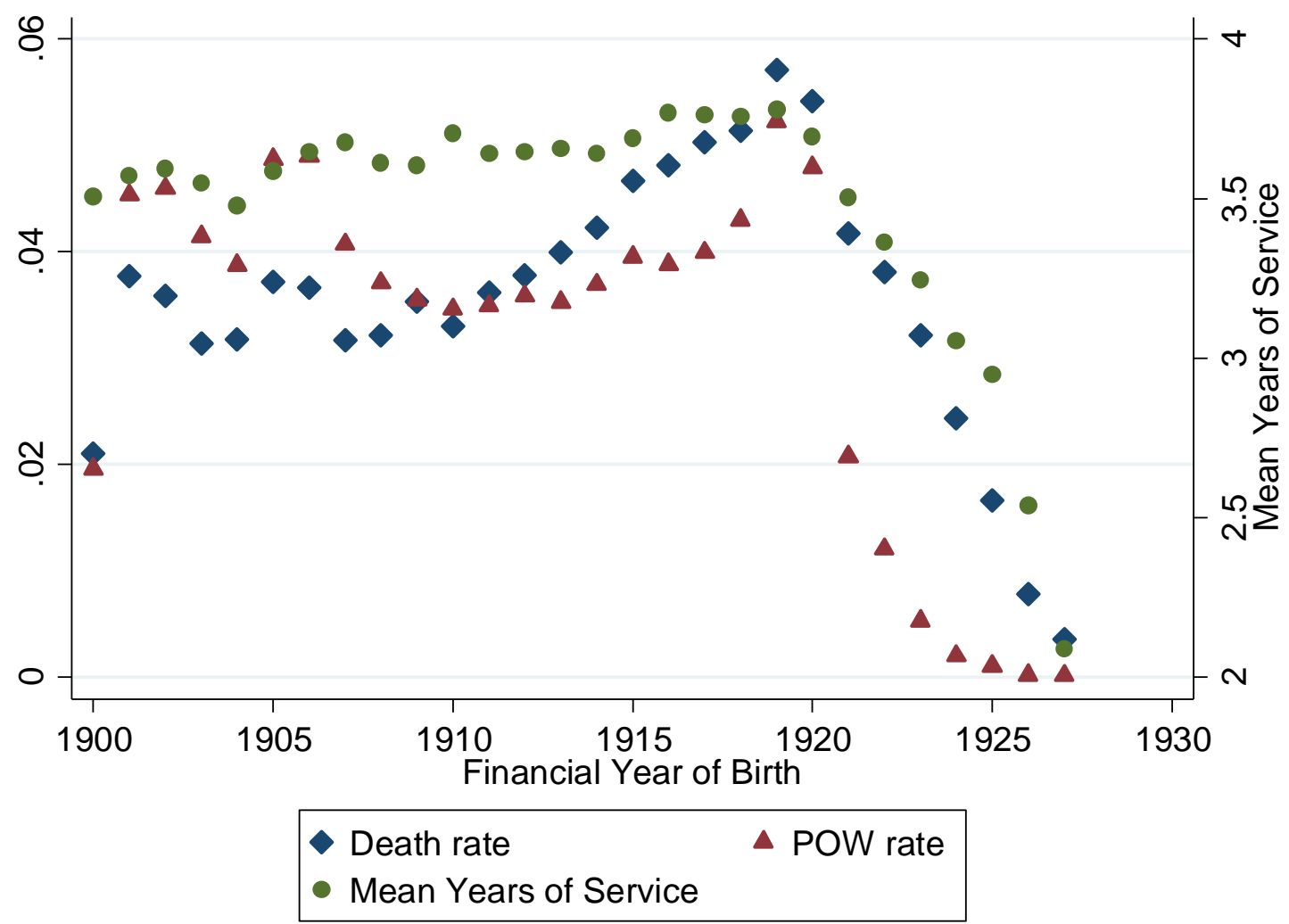

Notes: The figure shows three proxies of service intensity by birth year, each calculated from the WW2 Nominal Roll. For parsimony, 1900 refers to the 1899-1900 financial year birthcohort, similarly for the other years. 

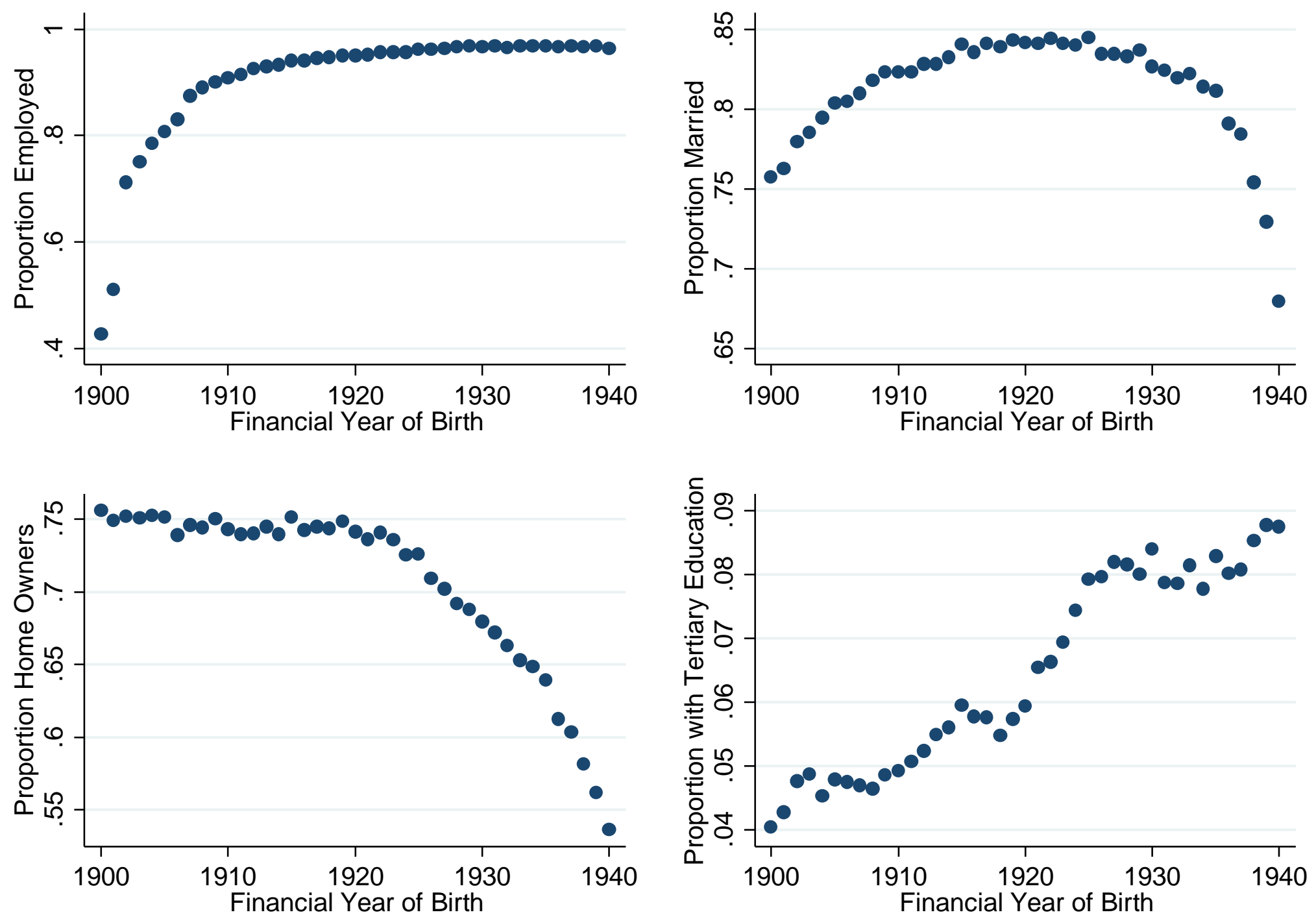

Source: 1966 Census of Population and Housing. Males who arrived in Australia after WW2 are excluded. 
A) Military Service by Age with Cubic Fit

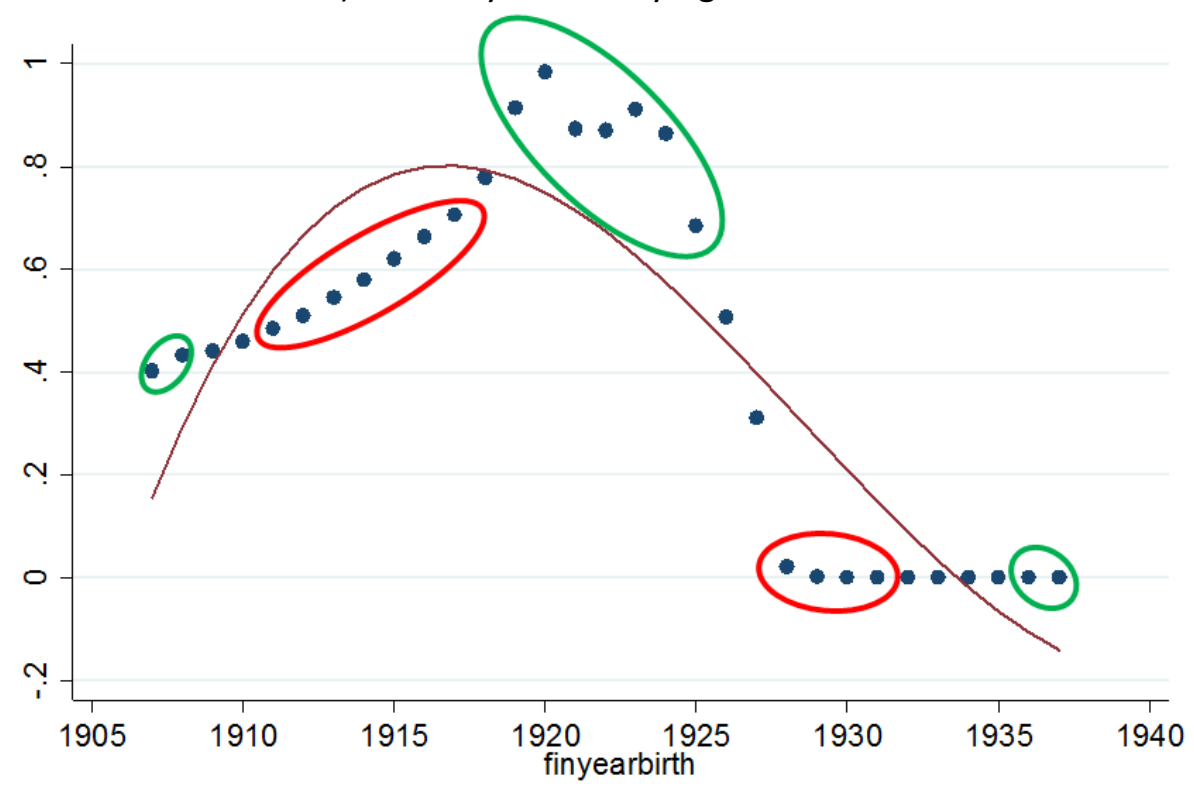

B) Employment by Age with Cubic Fit

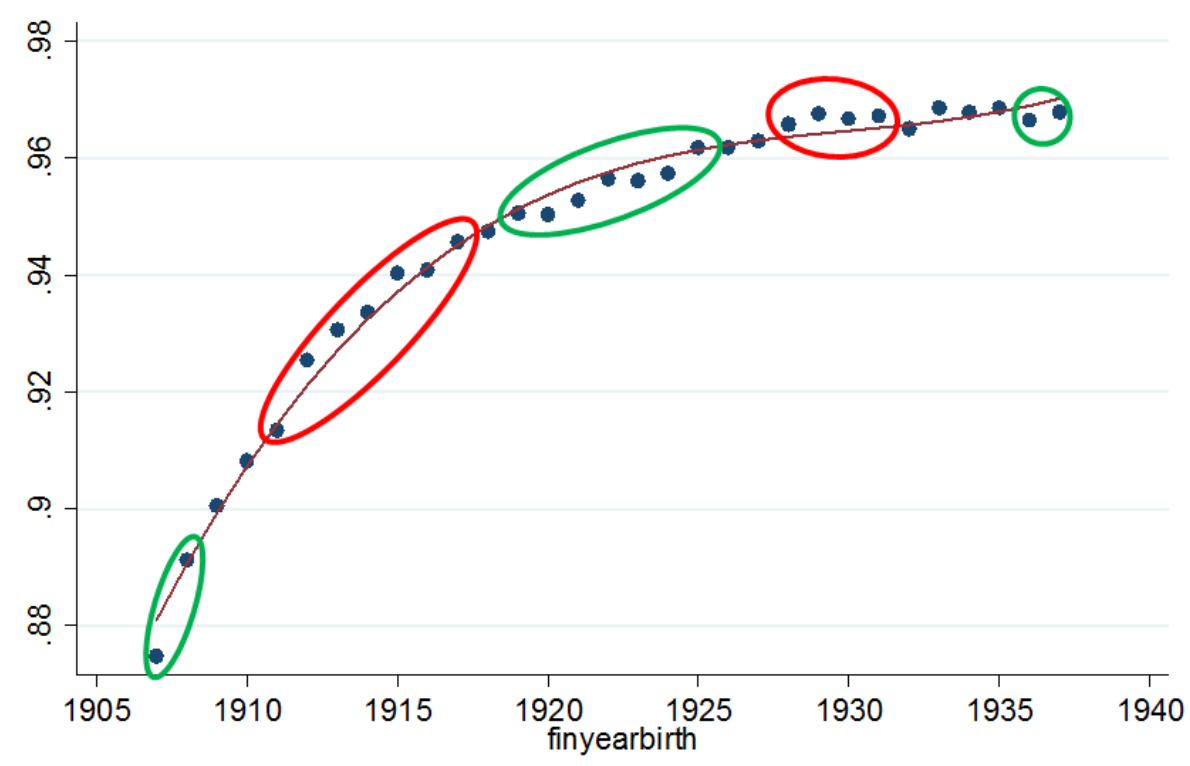

C) Relationship between the residuals from the first two Frisch-Waugh regressions

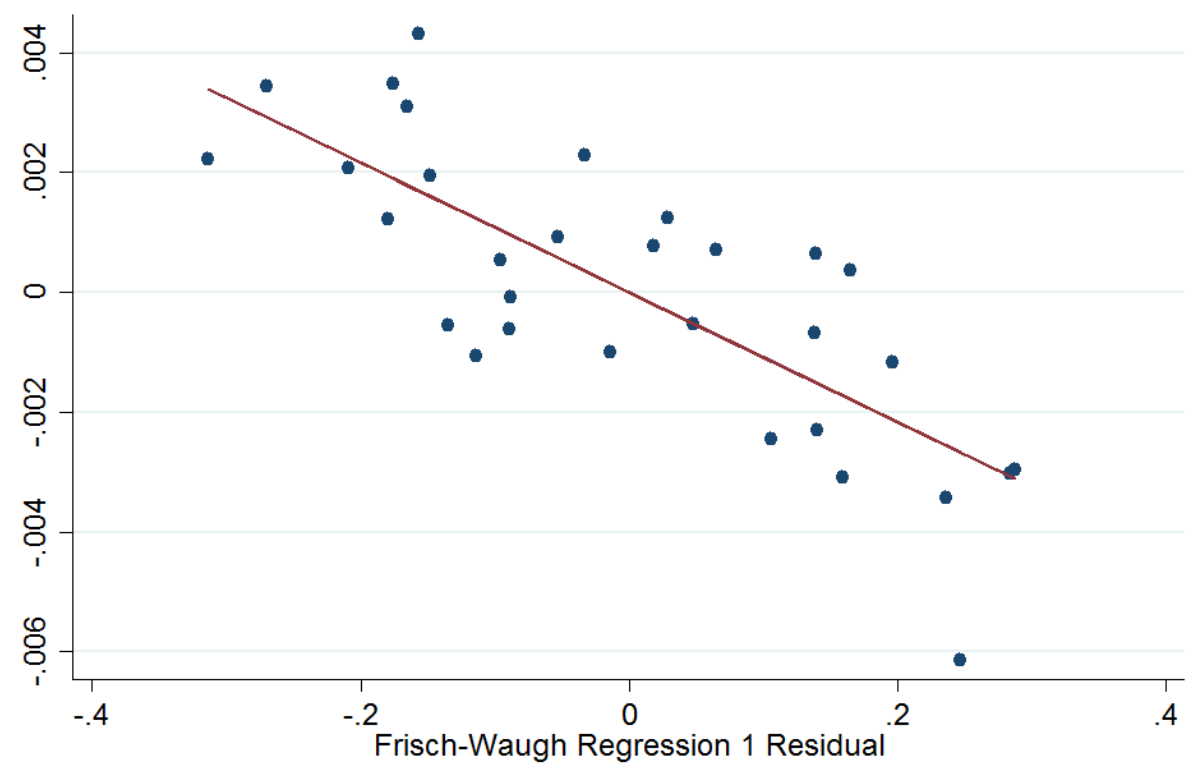


Notes: This figure is a visual depiction of the variation that identifies the effect of military service on employment. Panels A and B shows scatter plots with superimposed cubic fits which correspond to the first two Frisch-Waugh regressions. Panel $\mathrm{C}$ shows the relationship between the residuals from the first two Frisch-Waugh regressions. See text for an interpretation of these graphs. 